\title{
Signal Transducer and Activator of Transcription 5A
}

National Cancer Institute

\section{Source}

National Cancer Institute. Signal Transducer and Activator of Transcription 5A. NCI

Thesaurus. Code C28668.

Signal transducer and activator of transcription 5A (794 aa, 91 kDa) is encoded by the human STAT 5A gene. This protein is involved in transcriptional regulation, signal transduction and the metabolism of amino acids, carbohydrates and purines. 